Major American Universities Ph.D.

Qualifying Questions and Solutions - Mathematics

\title{
Problems and
}

\section{Solutions in}

\section{Mathematics}

Second Edition 
This page intentionally left blank 
Major American Universities Ph.D.

Qualifying Questions and Solutions - Mathematics

\section{Problems and}

Solutions in

\section{Mathematics}

Second Edition

Compiled by:

Chen Ji-Xiu, Jiang Guo-Ying,

Pan Yang-Lian, Qin Tie-Hu, Tong Yu-Sun, Wu Quan-Shui and Xu Sheng-Zhi

Edited by

Li Ta-Tsien

Fudan University, China 


\section{Published by}

World Scientific Publishing Co. Pte. Ltd.

5 Toh Tuck Link, Singapore 596224

USA office: 27 Warren Street, Suite 401-402, Hackensack, NJ 07601

UK office: 57 Shelton Street, Covent Garden, London WC2H 9HE

\section{British Library Cataloguing-in-Publication Data}

A catalogue record for this book is available from the British Library.

\section{Major American Univ. Ph. D. Qualifying Questions and Solutions - Mathematics PROBLEMS AND SOLUTIONS IN MATHEMATICS}

\section{Second Edition}

Copyright (C) 2011 by World Scientific Publishing Co. Pte. Ltd.

All rights reserved. This book, or parts thereof, may not be reproduced in any form or by any means, electronic or mechanical, including photocopying, recording or any information storage and retrieval system now known or to be invented, without written permission from the Publisher.

For photocopying of material in this volume, please pay a copying fee through the Copyright Clearance Center, Inc., 222 Rosewood Drive, Danvers, MA 01923, USA. In this case permission to photocopy is not required from the publisher.

ISBN-13 978-981-4304-95-5

ISBN-10 981-4304-95-6

ISBN-13 978-981-4304-96-2 (pbk)

ISBN-10 981-4304-96-4 (pbk)

Typeset by Stallion Press

Email: enquiries@stallionpress.com

Printed in Singapore. 


\section{Preface}

This book covers six aspects of graduate school mathematics: Algebra, Topology, Differential Geometry, Real Analysis, Complex Analysis and Partial Differential Equations. It contains a selection of more than 500 problems and solutions based on the $\mathrm{Ph}$.D. qualifying test papers of a decade of influential universities in North America. The mathematical problems under discussion are kept within the scope of the textbooks for graduate students. Finding solutions to these problems, however, involves a deep understanding of mathematical principles as well as an acquisition of skills in analysis and computation. As a supplement to textbooks, this book may prove to be of some help to the students in taking relevant courses. It may also serve as a reference book for the teachers concerned.

It has to be pointed out that this book should not be regarded as an all-purpose troubleshooter. Nor is it advisable to take the book as an exemplary text and commit to memory all the problems and solutions and make an indiscriminate use of them. Instead, the students are expected to make a selective survey of the problems, take a do-it-yourself approach and arrive at their own solutions which they may check against those listed in the book. It would be gratifying to see that the students can work out the problems on their own and come up with better solutions than those provided by the book. If the students fail to do so or their solutions may turn out to be incomplete, it may reveal the inadequacy of their knowledge or approach, thus spurring them to greater efforts to promote their skills. The very purpose of 
the authors in writing the book is just to help the students to discover the truth by trial and error.

This book was inspired by Professor K. K. Phua's proposals. We are particularly grateful to him for his support. We also wish to thank Dr. Xu Pei-jun, Professors Zhang Yin-nan, Hong Jiaxing and Chen Xiao-man for their painstaking efforts to collect test-oriented data. For selecting problems and providing solutions, we wish to acknowledge the following professors respectively: Wu Quan-shui (Part I), Pan Yang-lian (Part II), Jiang Guo-ying (Part III), Tong Yu-sun, Xu Sheng-zhi (Part IV), Chen Ji-xiu (Part V) and Qin Tie-hu (Part VI). We are also indebted to Professor Guo Yu-tao for carefully reading and correcting the manuscript. Finally, we pay tribute to Dr. Cai Zhi-jie for printing out the manuscript.

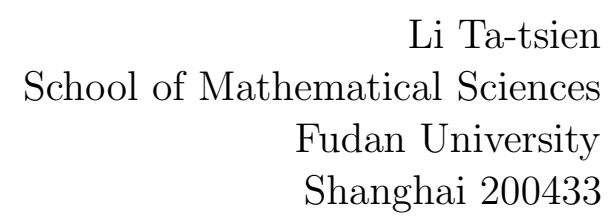

China 


\section{Preface to the Second Edition}

It has been twelve years since the first publication of this book. During the period, new mathematical problems, including many classical and interesting ones, kept emerging in the Ph.D. Qualifying Test of some prestigious universities in North America. For the improvement of this book and with the encouragement of World Scientific Publishing Co., we carefully selected more than one hundred new mathematical problems from the Ph.D. Qualifying Test papers in the past decade and provided solutions to them respectively, which can be taken as a necessary supplement to the first edition. Besides, we also made suitable corrections or amendments to the first edition regarding the solutions to a few problems which were not written in a very clear way or contained loopholes. We hope that the second edition of the book will be more helpful to readers.

Finally, on this occasion, we would like to express our gratitude to the readers for their concern and to the World Scientific for their support.

Li Ta-tsien School of Mathematical Sciences Fudan University Shanghai 200433

China 
This page intentionally left blank 


\section{Contents}

Preface $\quad$ V

Preface to the Second Edition vii

$\begin{array}{lll}\text { Part } 1 & \text { Algebra } & 1\end{array}$

Section $1 \quad$ Linear Algebra 3

Section 2 Group Theory 33

Section $3 \quad$ Ring Theory 55

Section 4 Field and Galois Theory 73

$\begin{array}{lll}\text { Part 2 } & \text { Topology }\end{array}$

Section $1 \quad$ Point Set Topology 121

Section 2 Homotopy Theory 143

Section 3 Homology Theory 171

Part $3 \quad$ Differential Geometry 215

Section $1 \quad$ Differential Geometry of Curves 217

Section 2 Differential Geometry of Surfaces 241

Section 3 Differential Geometry of Manifolds 287

$\begin{array}{lll}\text { Part } 4 & \text { Real Analysis } & 347\end{array}$

Section $1 \quad$ Measurability and Measure 349

Section 2 Integral 389

Section $3 \quad$ Space of Integrable Functions 433 
Section $4 \quad$ Differential

Section 5

Miscellaneous Problems

Part 5

Complex Analysis

503

Section 1

Analytic and Harmonic Functions

505

Section 2

Geometry of Analytic Functions

Section 3

Complex Integration

Section 4

The Maximum Modulus and

Argument Principles

615

Section 5

Series and Normal Families

Part 6

Partial Differential Equations

Section 1

General Theory

677

Section 2

Elliptic Equations

697

Section 3

Parabolic Equations

729

Section 4

Hyperbolic Equations

755

Abbreviations of Universities in this Book

793 